\title{
Evaluation Model of Simulation Based Training for Helicopter Emergency Rescue Mission
}

\author{
Xiaoming Chen ${ }^{1}, \mathrm{Hu} \mathrm{Liu}^{1}$, Jinpeng $\mathrm{Bai}^{2}$ and $\mathrm{Zhe} \mathrm{Wu}^{1}$ \\ ${ }^{1}$ School of Aeronautical Science and Engineering, Beihang University, Beijing, China \\ ${ }^{2}$ Shenyang Aircraft Design and Research Institute, Shenyang, China \\ mchende@qq.com
}

\begin{abstract}
Helicopter emergency rescue plays an important role in the system of aviation emergency rescue. Regular training for helicopter emergency rescue mission is difficult to be carried out because of the dangerous environment and high cost. However, simulation based training is the essential means to improve the operating ability of helicopter emergency rescue team. A virtual training environment called Helicopter Emergency Rescue Mission Training System (HERMTS) was designed and developed for helicopter emergency rescue training. An evaluation model based on Kirkpatrick's model was established to evaluate the training effectiveness. The training effectiveness was described by mission effectiveness matrix. The results showed that trainees made positive comments on HERMTS and the HERMTS was effective to promote their capacity of forest firefighting mission.
\end{abstract}

Keywords: Training effectiveness evaluation; Kirkpatrick's model; Mission effectiveness matrix; simulation based training; Helicopter emergency rescue

\section{Introduction}

With the development of virtual simulation technology, Simulation Based Training (SBT) has been increasingly applied to training programs in various fields. The major advantage of SBT is that it can simulate the environment which is characterized by dangerous or reproduce-difficult. The typical scenes are the rescue training of earthquake and fire disaster, even SBT is the only option for these scenes[1]. SBT has different patterns, including Computer Based Training (CBT) [2], Web Based Training (WBT) [3] and Immersive Virtual Reality System Based Training (IVRSBT) [4,5]. CBT, which is generally operated on single computer, creates a training environment for students with the manners of images, voice, text and simulation-based operation. WBT is similar to CBT, however, since WBT is operated on the basis of web browser, it is more convenient for students to training without time and place limits. WBT is more affected by network condition. Compared with CBT and WBT, IVRSBT has the incomparable advantages in constructing immersive environment and human-computer interaction on the expense of high cost.

As an important part of the system of aviation emergency rescue, helicopter emergency rescue (forest firefighting, earthquake relief et al.) is in the process of rapid growing with the characters of quick, accurate and less affected by space constraints. Related training for the helicopter emergency rescue plays a major role in the construction of the system of aviation emergency rescue, but it has some deficiencies currently. (1) The environment of emergency rescue is usually extremely complex and dangerous and the disaster scene is difficult to reproduce, so the training is constrained by lack of lifelike environment. (2) Taking the high cost and risk into account, there is low possibility to train with real helicopter. (3) The flight simulator widely used in the flight training attaches more importance to flying skills of pilots. The helicopter emergency rescue, however, focuses 
on not only the pilot's flying skills, but also the coordination abilities of the crew to fulfill the rescue mission. Therefore, the traditional flight simulator is useless for helicopter emergency rescue training.

SBT is an effective measure to solve the problems above. Helicopter Emergency Rescue Mission Training System (HERMTS) was a distributed virtual training environment and was developed for complex collaborative missions such as helicopter forest firefighting and earthquake relief. Figure 1 shows the structure of HERMTS. Taking helicopter forest firefighting training as an example, the system consisted of visual display client, mission operation client (including pilot, observer, machinist, operator and navigator) and control center. The clients formed a distributed virtual training environment through the Ethernet switch.

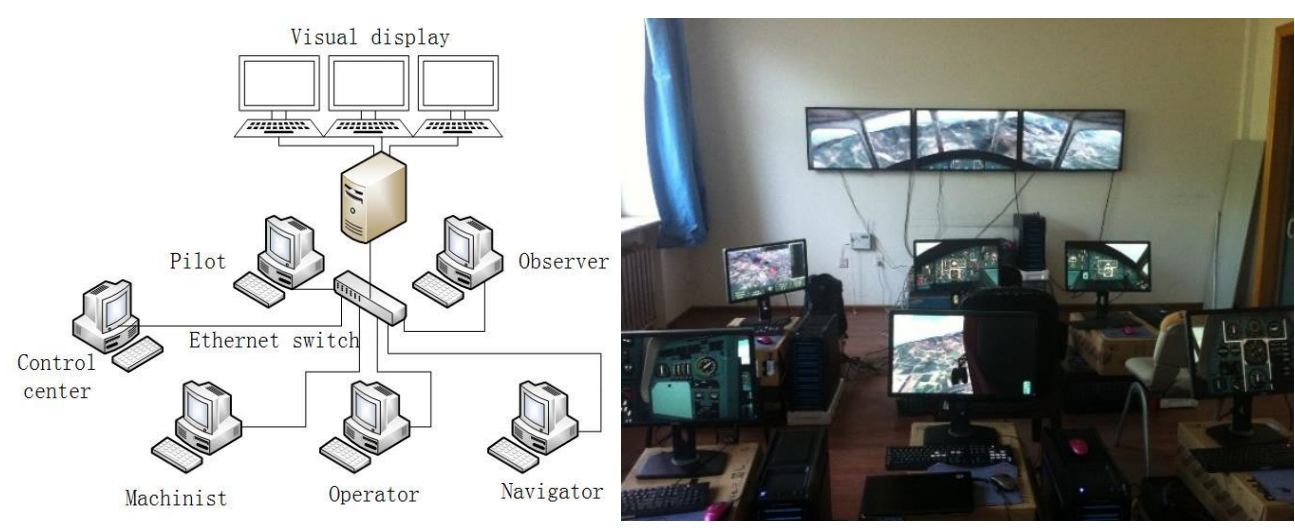

\section{Figure 1. A Virtual Training Environment for Helicopter Emergency Rescue Mission}

Forest firefighting with helicopter is one of the major means of aviation forest firefighting [6], however, related training work has been difficult to be carried out because of the high cost and lack of training condition. The HERMTS developed a virtual training environment and the virtual helicopter was based on MI-26, which was a type of heavy transport helicopter. In the HERMTS, the control center was designed to set mission parameters (the position and intensity of fire, altitude, wind speed and weather) at the beginning of training, monitor the training process and trigger special circumstances in the process of training. The pilot was responsible for the manipulation of the helicopter. The observer was responsible for observing complex environment around the fire. The navigator was responsible for location tracking of helicopter, fire and the source of water. The machinist was responsible for monitoring the running state of each system to ensure a healthy condition of the helicopter. The operator was responsible for operating the bucket to put out fire with water. Figure 2 shows the training scene of HERMTS. 


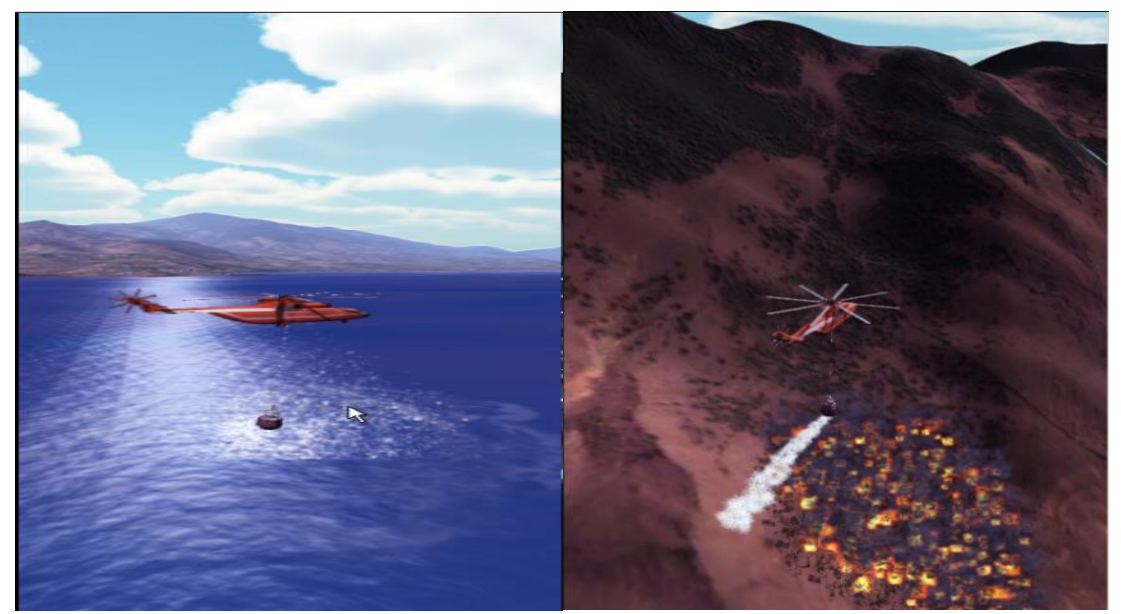

Figure 2. Firefighting Mission Training Based on HERMTS

To complete the firefighting mission successfully, it requires the proficient flying skills of pilot, yet the coordination abilities of the crew. Training evaluation, which is the auxiliary decision measure to improve the training method and optimize the training process, is an important part of the whole training process [7], see Figure 3.

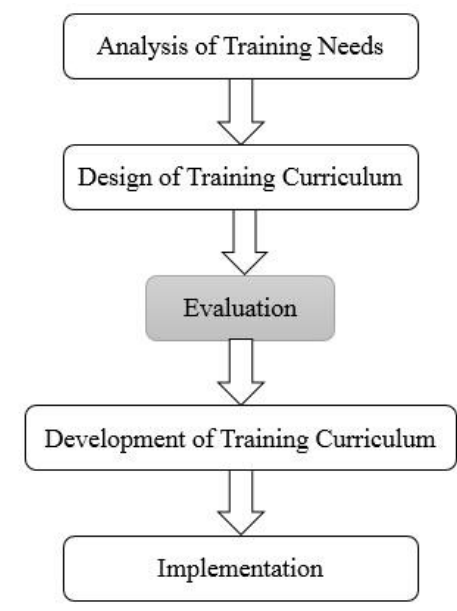

Figure 3. The Systematic Training Model

The researchers of various fields have carried out theoretical exploration and practice on the evaluation of training effectiveness. P. Andreatta et al. made efforts to improve the ability of birth attendants to correctly perform bimanual uterine compression with postpartum hemorrhage simulator and then evaluated the training effectiveness [8]. B. F. Antle et al. established a theoretical model to evaluate the children warfare training [9]. S. A. M. A. Khatwah set up a virtual training classroom and evaluated its effect on improving the learning skills of faculty [10]. Y. B. Son et al. evaluated the effect of the CBT (Computer Based Training) on artillery virtual maintenance training with the method of controlled trials[11]. L. Zheng et al. evaluated the effect of e-training on the teaching skills training of primary and secondary school teachers [12]. S. Yang et al. researched the evaluation method of manager training [13].

In the field of flight vehicle simulation based training, a flight simulator training performance evaluation system has been developed to evaluate the flying skills of pilot $[14,15]$, it was a standardized test evaluation system. References [16-18] established an evaluation model of military confrontation training effectiveness based on combat effectiveness of equipment, but it didn't develop a virtual training environment. The 
police training department of a German federal state has been conducting a large project to develop a virtual training environment called VTE ViPOL with the object of providing adequate training for complex collaborative tasks [19]. HERMTS and VTE ViPOL shared the characteristics of supporting complex environment and multi-trainee.

This paper developed a virtual training environment for forest firefighting with helicopter. In the following section, an evaluation model would be established to assess the training effectiveness and an illustration was conducted.

\section{Preparation for Modeling}

\subsection{The Characteristics of Effectiveness Evaluation of Helicopter Emergency Rescue}

The influencing factors of training effectiveness can be classified as two parts, namely nontechnical factors, including learning attitude and interest et al., and technical factors such as learning ability and knowledge reserved et al. The previous studies, however, attached much more importance to technical factors than nontechnical factors. The learning attitude and interest are of vital significance for training effectiveness, which should be taken into consideration while evaluating the training effectiveness.

As to the virtual simulation training for helicopter emergency rescue, the mission effectiveness was paid more attention instead of the flying skills of pilot (the crew of emergency rescue should master basic helicopter operating knowledge). The mission effectiveness could be described by the degree of mission fulfillment and the coordination abilities of the crew. The degree of mission fulfillment was measured by some objective indexes and these indexes could be obtained from simulation results. By contrast, the coordination abilities of the crew was graded directly by expert trainer.

\subsection{Introduction to Kirkpatrick's Model}

Kirkpatrick's model consists of four levels, including reaction, learning, behavior and results [20]. The first level is to measure the trainee's response for training. The second level is to measure the degree they can realize in the knowledge and skill expansion after training. The third level, yet called training transfer, focuses on whether trainees can apply the knowledge and skills they learned from the training to the job. The last level evaluates the total cost and profit at organizational level.

Because of the concise and systematic classification for evaluation criteria, Kirkpatrick's model is popular in the business world and academia [21]. However, the model is to some degree rough. Alliger et al. provided a more detailed instruction of Kirkpatrick's model [22], see Table 1.

Table 1. Detailed Instruction of Kirkpatrick's Model

\begin{tabular}{cc}
\hline Kirkpatrick's model & Detailed instruction of Kirkpatrick's model \\
\hline Reactions & Reactions \\
Learning & Affective reactions \\
& Utility reactions \\
& Learning \\
Immediate knowledge & Knowledge retention \\
Behavior & Behavior/skill demonstration \\
Results & Transfer \\
& Results \\
& Productivity \\
& Customer satisfaction \\
& Cost savings
\end{tabular}


Morale

\section{Evaluation Model: a Framework}

Though Kirkpatrick's model suggested that evaluation can be conducted from four dimensions, it didn't provided the concrete methodology. It is essential to establish the evaluation model according to the characteristics of the mission of forest firefighting with helicopter.

Kirkpatrick's model is not easy to be carried out from the first level to the fourth level. Taking forest firefighting with helicopter as an example, it is difficult to realize a controlled experiment which requires real helicopter to put out forest fire, because of the dangerous scenario and high cost. A simplified Kirkpatrick's model involving reaction and learning evaluation was used to assess the training effectiveness of simulation based training for helicopter emergency rescue mission.

\subsection{STEP 1: Reaction Evaluation}

When training was completed, all participants were required to make comments on the training from two dimensions using Likert scale, which was a rating scale ranging from 1 to 5 (1-strongly disagree, 2-disagree, 3-neutral, 4-agree, 5-strongly agree): (1) for affective reactions and (2) for utility reactions.

Table 2. Themes from Comments about the Simulation-Based Training

\begin{tabular}{l}
\hline Affective reactions \\
\hline The training can completely meet my expectations \\
The training can help me to do the work better \\
The data used in the training was of great help to my understanding \\
This training can help me quickly master the skills of emergency rescue \\
\hline Utility reactions \\
Visual simulation was close to the actual operation of visual sense, no sense of delay \\
Helicopter simulation in such aspects as controllability, stability and fuel properties was \\
consistent with the actual \\
Bucket with the helicopter motion trend was consistent with the actual, and its dynamic \\
response was correct \\
Terrain was consistent with the actual elevation. the fire and the smoke was lifelike, and \\
the spread speed of fire line can be identified \\
Monitoring perspective was diversiform, which can effectively monitor the training \\
process \\
The system response was in a timely manner
\end{tabular}

\subsection{STEP 2: Learning Evaluation}

Effectiveness, which is associated with the inherent ability of the system, is the degree of meeting the requirements of a specific set of tasks under specified conditions and within the stipulated time. Mission Effectiveness is not also related to the inherent ability of the system, but also depends on the operators' own ability and the coordination abilities of the crew. Immediate knowledge, as well as knowledge retention, can be described with the variation of Mission Effectiveness. 


\subsubsection{Establishment of Indexes System}

The helicopter forest firefighting training based on HERMTS aimed to improve the firefighting skills and the coordination abilities of the crew. Thus, two types of index were chosen to establish the indexes system: Mission indexes and Collaboration indexes.

Mission indexes. Mission indexes were proposed to measure the quality of firefighting and usually derive from simulation results. There are firefighting rate, effectiveness-cost and time factor in mission indexes.

(1) firefighting rate $r_{\text {Fighting-Rate }}$

Where:

$$
r_{\text {Fighting-Rate }}=\frac{A_{\text {Dead }}}{A_{\text {Burned }}}
$$

$A_{\text {Dead }}:$ The fire area which has been put out.

$A_{B \text { и }{ }_{n} \text { : }}$ : The burned area, including the initial fire area and the spread fire area, represents the property loss.

When $r_{\text {Fighting-Rate }}$ is less than a certain threshold value, it means that the fire is out of control and the mission has failed. Therefore, $r_{\text {Fighting-Rate }}$ is determined by equation (2).

$$
r_{\text {Fighting-Rate }}=\left\{\begin{array}{cc}
0 & r_{\text {Fighting-Rate }}<0.4 \\
r_{\text {Fighting-Rate }} & r_{\text {Fighting-Rate }} \geq 0.4
\end{array}\right.
$$

effectiveness-cost $r_{\text {Effectiveness-Cost }}$

$$
r_{\text {Effectiveness-Cost }}=\frac{m_{\text {Water }}}{m_{\text {Fuel }}}
$$

Where:

$m_{\text {Water }}$ : The total quantity of water used to put out the fire, which represents the workload.

$m_{\text {Fuel }}:$ The consumption of fuel, which is one of the main factors of cost.

(3) time factor $r_{T}$

Where:

$$
r_{T}=\frac{1}{T}
$$

$T$ : The time consumption from the beginning of mission to the end. The end of mission means that all the fire area has been put out or the mission is forced to be stopped due to the uncontrolled fire.

Collaboration indexes. As to the mission of firefighting with helicopter, team cooperation was of significance. Collaboration Indexes were proposed to measure the coordination abilities of the crew, including the following three items.

(1) The rationality of firefighting strategy. The firefighting strategy has large influence on firefighting mission and it is related to the time consumption and control the fire timely.

(2) The proficiency of the crew working in cooperation. The proficiency of the crew grows in the process of simulation based training. It is an important sub-index of collaboration indexes.

(3) The ability to deal with unexpected incidents. It may come across various unexpected incidents when put out the fire with helicopter, such as critical air 
condition, failure of engine.

Different from the mission indexes, the collaboration indexes are scored by experts. Equality (5) is used to assess the collaboration indexes.

$$
r_{i j}=\frac{1}{p} \sum_{k=1}^{p} r_{i j, \mathrm{k}}
$$

In equation (5), $r_{i j}$ represents the collaboration indexes of Sub-Hierarchy as shown in Figure 4. $p$ is the number of experts and $r_{i j, \mathrm{k}}\left(1 \leq r_{i j, k} \leq 9\right)$ means the score of $r_{i j}$ given by expert $k(k=1,2, \cdots p)$.

Hierarchical model of indexes. Based on the above analysis, the hierarchical model of indexes system is naturally presented in Figure 4.

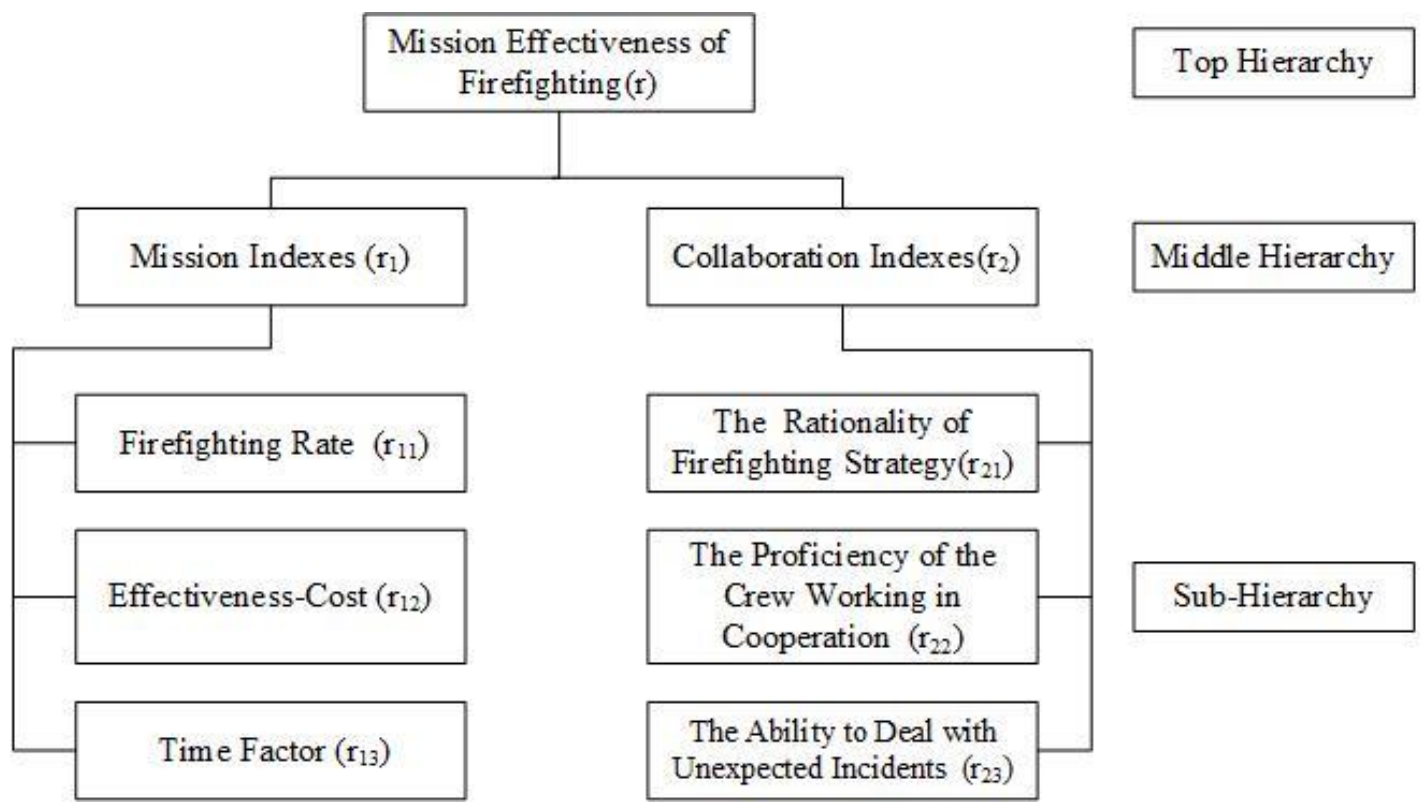

Figure 4. The Hierarchical Model of the Indexes System of Firefighting Mission Effectiveness

\subsubsection{Method to Determine the Weights of Indexes}

Based on the Delphi method, experts are invited to give weight value of each index subjectively. Assuming the number of the experts is $p$, the number of the indexes is $n$, and the weight of each index given by the experts is $x_{i j}(i=1,2, \cdots p \quad j=1,2, \cdots \mathrm{n})$, we can get the correlation coefficient $\xi_{j k}$

$$
\xi_{j k}=\frac{1}{p-1} \sum_{i=1}^{p} x_{i j} x_{i k} \quad(j, k=1,2, \ldots, n)
$$

Further, we can get the correlation matrix $A\left(\xi_{j k}\right)$ 


$$
A\left(\xi_{j k}\right)=\left[\begin{array}{cccc}
\xi_{11} & \xi_{12} & \cdots & \xi_{1 n} \\
\xi_{21} & \xi_{22} & \cdots & \xi_{2 n} \\
\vdots & \vdots & \vdots & \vdots \\
\xi_{n 1} & \xi_{2 n} & \cdots & \xi_{n n}
\end{array}\right]
$$

Then

$$
P_{k}=\sqrt[n]{\prod_{j=1}^{n} \xi_{j k}} \quad(k=1,2, \ldots, n)
$$

Finally, we can get the weigh value of each index as follow.

$$
\omega_{k}=\frac{P_{k}}{\sum_{k=1}^{n} P_{k}}
$$

\subsubsection{Method to Compute Mission Effectiveness}

The following problems exist among the index values. Firstly, because of the different dimensions of indexes, it is not easy to compare with each other. Secondly, the difference between the index values is large, even in different magnitudes, which is not convenient to conduct mathematical operations [23].

The solutions of the problems above are usually range transformation, linear transformation and vector transformation. These methods require extreme values of indexes (maximum and minimum). However, the indexes in this article do not have specific scope, so the above methods are inapplicable. It is effective to bring in the Comparison Matrix to solve this problem.

As shown in Figure 4, the symbols of each hierarchy are $r, r_{i}$ and $r_{i j}$ in order.

Similarly, we define the meaning of symbols as follows, where $t, n_{i}$ and $m$ are counting units.

$r_{i}(1 \leq i \leq m)$ : The indexes of Middle Hierarchy.

$r_{i j}\left(1 \leq j \leq n_{i}\right):$ The indexes of Sub-Hierarchy.

$e_{\alpha}(1 \leq \alpha \leq t)$ : The codename of training mission.

The Comparison Matrix can be described by the following equation.

$$
R_{i}^{(\alpha)}=\left(r_{i j}^{(\alpha)}\right)_{t \times n_{i}}
$$

Where $r_{i j}^{(\alpha)}$ takes the place of $r_{i j}$ when the symbol $e_{\alpha}$ is brought in.

Based on the normalization method, we can get

$$
s_{i j}^{(\alpha)}=\frac{r_{i j}^{(\alpha)}}{\sum_{\alpha=1}^{t} r_{i j}^{(\alpha)}}\left(1 \leq \alpha \leq t, 1 \leq j \leq n_{i}\right)
$$

Further, the Standard Comparison Matrix is obtained.

$$
S_{i}^{(\alpha)}=\left(s_{i j}^{(\alpha)}\right)_{t \times n_{i}}
$$

As to the Standard Comparison Matrix $S$, the sum of the elements of each column is 1 . That is to say 


$$
\sum_{\alpha=1}^{t} s_{i j}^{(\alpha)}=1 \quad\left(j=1,2, \ldots, n_{i}\right)
$$

Then, the indexes which belong to Middle Hierarchy satisfy the following equation.

$$
r_{i}^{(\alpha)}=\sum_{j=1}^{n_{i}} \omega_{i j} s_{i j}^{(\alpha)} \quad(\alpha=1,2, \ldots, \mathrm{t})
$$

Where $r_{i}^{(\alpha)}$ takes the place of $r_{i}$ when the symbol $e_{\alpha}$ is brought in and $\omega_{i j}$ can be obtained by equation (9).

Finally, the mission effectiveness of firefighting can be described by equation (15).

$$
r^{(\alpha)}=\sum_{i=1}^{m} \omega_{i} r_{i}^{(\alpha)}(\alpha=1,2, \ldots, \mathrm{t})
$$

Where $r^{(\alpha)}$ takes the place of $r_{r}$ when the symbol $e_{\alpha}$ is brought in and $\omega_{i}$ can be obtained by equation (9).

According to the Mission Effectiveness Matrix (MEM), we can easily evaluate the training effectiveness.

\section{Illustration: a Case Study}

\subsection{Design of Experiment}

Virtual simulation training was conducted including 3 helicopter emergency rescue teams (at different level, named Team A, Team B and Team C) and each team consisted of 5 members. The training program comprised pre-training, pre-assessment, training sessions, practice time and post-assessment. Firstly, the trainer lectured to the trainees basic knowledge about the HERMTS (pre-training). Then, the trainer set up the training mission and all teams were required to complete the mission in turn for the first time (pre-assessment). During the training sessions, the trainer provided details about the firefighting mission. Following the training sessions, the team members were allowed to practice with the HERMTS within one day. Team A and Team B completed the post-assessment immediately after the practice time. A week later, Team $\mathrm{C}$ completed it. Following the post-assessment, the third training and assessment was conducted to enhance the ability of each team.

\subsection{Result of Reaction}

In the reaction evaluation, all response distributed on the right side of the scale "neutral" (total scores=30), see Figure 5. Taking the total score 30 as reference value, there was a significant difference between the average total score (Mean=36.07) and the reference value, which demonstrated that all trainees made positive comments on the training. Though positive satisfaction ratings do not guarantee learning and subsequent application of training program, negative ratings mostly decrease the probability of them [24, 25]. It is also essential and important to get positive satisfaction ratings for both trainer and trainees. 


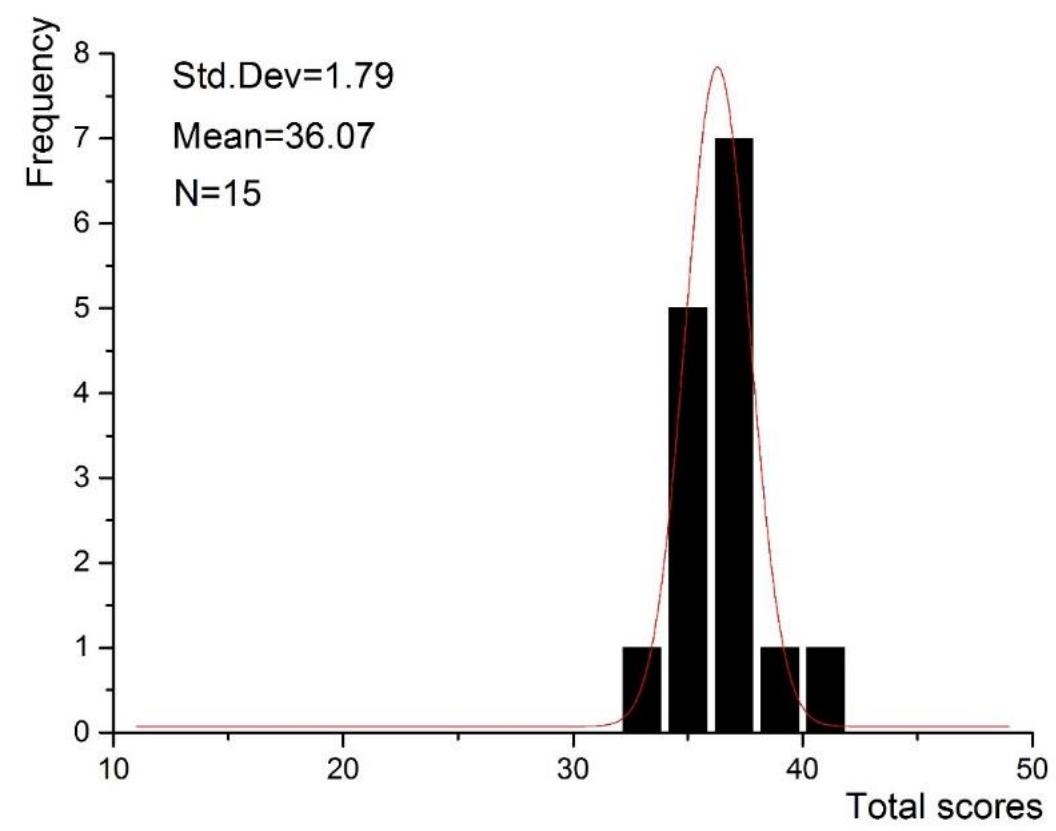

Figure 5. The Frequency Distribution of Reaction Total Score

\subsection{Result of Learning}

Four experts were invited to determine the weight value of each index, then it was easily to obtain the final weight value of each index with the method above, see Table 3 .

Table 3. Weight Value of Indexes

\begin{tabular}{cccccccc}
\hline$\omega_{1}$ & $\omega_{11}$ & $\omega_{12}$ & $\omega_{13}$ & $\omega_{2}$ & $\omega_{21}$ & $\omega_{22}$ & $\omega_{23}$ \\
\hline 0.5941 & 0.2129 & 0.3503 & 0.4368 & 0.4059 & 0.2129 & 0.3503 & 0.4368 \\
\hline
\end{tabular}

The assessment scores of three assessment (pre, post and the third) are shown in Table 4. For instance, Team A conducted training evaluation for three times, apparently, it made sustainable progress because of the training.

Table 4. Assessment Scores for Firefighting Mission

\begin{tabular}{cccccccc}
\hline \multirow{2}{*}{ Teams } & $e_{\alpha}$ & \multicolumn{3}{c}{ Mission indexes } & \multicolumn{3}{c}{ Collaboration Indexes } \\
\cline { 3 - 8 } & & $r_{11}$ & $r_{12}$ & $r_{13}$ & $r_{21}$ & $r_{22}$ & $r_{23}$ \\
\hline \multirow{3}{*}{$\mathrm{A}$} & 1 & 0 & 20.68 & $1 / 96$ & 5.2 & 4.4 & 3.6 \\
& 2 & 0.46 & 23.54 & $1 / 83$ & 6.4 & 5.1 & 7.3 \\
& 3 & 0.52 & 28.04 & $1 / 70$ & 7.0 & 7.2 & 8.7 \\
\hline \multirow{3}{*}{$\mathrm{B}$} & 1 & 0 & 14.7 & $1 / 84$ & 6.1 & 5.4 & 4.3 \\
& 2 & 0.51 & 25.9 & $1 / 82$ & 7.2 & 6.4 & 6.5 \\
& 3 & 0.60 & 30.8 & $1 / 75$ & 7.0 & 8.1 & 8.0 \\
\hline \multirow{3}{*}{$\mathrm{C}$} & 1 & 0.56 & 48.4 & $1 / 86$ & 7.0 & 7.2 & 7.1 \\
& 2 & 0.86 & 52.8 & $1 / 72$ & 7.2 & 7.2 & 8.0 \\
& 3 & 1.0 & 60.3 & $1 / 62$ & 8.1 & 8.2 & 8.4 \\
\hline
\end{tabular}

All teams conducted three assessments, and the Mission Effectiveness Matrix of each team is shown as follow. 


$$
\begin{aligned}
& M E M_{\text {Team A }}=(0.227,0.351,0.421) \\
& M E M_{\text {Team B }}=(0.230,0.356,0.414) \\
& M E M_{\text {Team C }}=(0.289,0.333,0.377)
\end{aligned}
$$

\subsection{Discussion}

The three teams were at different levels. For the pre-assessment, Team A and Team B failed to complete the firefighting mission (Team A and Team B, $\mathrm{r}_{11}=0$ ), however, Team C performed better than Team A and Team B. The Mission Effectiveness Matrix of each team demonstrated that the HERMTS was effective for teams at different levels, because all the three teams expanded their skills and knowledge of firefighting mission.

For Team A and Team B, they conducted the post-assessment immediately after the training and practice, they both made obvious progress compared to the pre-assessment. By contrast, Team C completed the post-assessment a week later, because of the knowledge retention, its mission effectiveness still improved. The difference of mission effectiveness increment between Team A, B and Team C may attribute to the one-week interval, which decreased the proficiency of Team C.

\section{Conclusion}

Special training programs such as earthquake relief, forest firefighting with helicopter have been developing rapidly because of simulation based training. This paper established a virtual training environment called HERMTS for helicopter forest firefighting training, which is a typical complex collaborative mission. Based on the evaluation model, three teams' training effectiveness was assessed and the results were positive.

\section{References}

[1] D. M. Romano and P. Brna, "Cyber Psychology \& Behavior", vol. 2, no. 4, (2001).

[2] L. Malmsköld, R. Malmsköld and L. Svensson, "Human Factors and Ergonomics in Manufacturing \& Service Industries", (2014).

[3] K. Put, J. Wagemans, A. Jaspers and W. F. Helsen, "Psychology of Sport and Exercise", vol. 4, no. 14, (2013).

[4] C. Noon, R. Zhang, E. Winer, J. Oliver, B. Gilmore and J. Duncan, "Computers in Industry", vol. 5, no. 63, (2012).

[5] M. Kozhevnikov and J. Gurlitt, Editors. "Immersive and Non-immersive Virtual Reality System to Learn Relative Motion Concepts", Interdisciplinary Engineering Design Education Conference; Santa Clara, America, March 4-5 (2013).

[6] C. Shang and K. Wang, "Forestry Machinery \& Woodworking Equipment", vol. 3, no. 41, (2013).

[7] M. L. McGinnis and G. F. Stone III, Editors. "Measuring the Effectiveness of Simulation-based Training", Proceedings of the 28th Conference on Winter Simulation; Washington, DC, America, November (1996).

[8] P. Andreatta, F. Gans-Larty, D. Debpuur, A. Ofosu and J. Perosky, "International Journal of Nursing Studies", vol. 10, no. 48, (2011).

[9] B. F. Antle, A. P. Barbee and M. A. Van Zyl, "Children and Youth Services Review", vol. 9, no. 30, (2008).

[10] S. A. M. A. Khatwah, Editors. "Design an Innovative Virtual Training Environment and Measure Their Effectiveness in the Development of e-Learning Skills Training and the Trend towards Default with Faculty Members", 2013 Fourth International Conference on e-Learning "Best Practices in Management, Design and Development of e-Courses: Standards of Excellence and Creativity"; Manama, Bahrain, May 7-9 (2013).

[11] Y. B. Son and D. W. Park, Editors. "Effectiveness and analysis of on-line CBT artillery maintenance military simulation training", 2012 8th International Conference on Information Science and Digital Content Technology; Jeju Island, Korea, June 26-28 (2012).

[12] L. Zheng, R. Huang and J. Yu, Editors. "Evaluation of the Effectiveness of E-Training: A Case Study on In-Service Teachers' Training", 2013 IEEE 13th International Conference on Advanced Learning Technologies; Beijing, China, July 15-18 (2013). 
[13] S. Yang and Q. Zhu, Editors. "Research on Manager Training Effectiveness Evaluation Based on Kirkpatrick Model and Fuzzy Neural Network Algorithm”, WiCOM2008 4th International Conference on Wireless Communications, Networking and Mobile Computing; Dalian, China, October 12-14 (2008).

[14] J. Zhang, X. Li and S. Ni, "Journal of Air Force Engineering University (Natural Science Edition)”, vol. 1, no. 2, (2001).

[15] X. Gao, Z. Wang and X. Zhou, "Modern Electronics Technique”, vol. 24, no. 35, (2001).

[16] Q. Chen, N. Jiang, M. Lu and S. Rao, "System Engineering and Electronics", vol. 6, no. 35, (2013).

[17] Q. Chen, S. Zhao and N. Jiang, "Command Control \& Simulation”, vol. 2, no. 35, (2013).

[18] Y. Liu, G. Wang, D. Feng and H. Zhang, "Journal of System Simulation", vol. 17, no. 21, (2009).

[19] J. Bertram, J. Moskaliuk and U. Cress, "Computers in Human Behavior", vol. 43, (2015).

[20] D. L. Kirkpatrick, "Training and Development Journal", vol. 33, (1979).

[21] S. Shelton and G. M. Alliger, "Training and Development", vol. 6, no. 47, (1993).

[22] G. M. Alliger, S. I. Tannenbaum, W. Bennett, H. Traver and A. Shotland, "Personnel Psychology", vol. 2, no. 50, (1997)

[23] J. Zhang and H. Tang, Editor, "Research on Effectiveness Evaluation Method", National Defence Industry Press, Beijing, (2009).

[24] T. T. Baldwin and J. K. Ford, "Personnel Psychology", vol. 1, no. 41, (1988).

[25] J. J. Phillips, Editor, "Handbook of Training Evaluation and Measurement Methods", Routledge, New York, (1997).

\section{Authors}

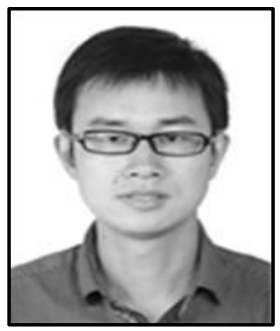

Xiaoming Chen, he is a Master degree candidate in School of Aeronautical Science and Engineering, Beihang University. His research interests include aircraft conceptual design, system simulation and effectiveness evaluation.

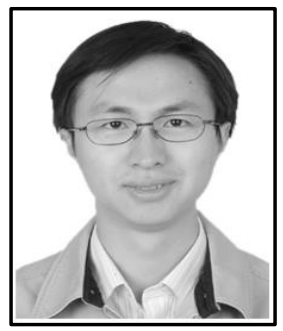

Hu Liu, he is an associate professor in School of Aeronautical Science and Engineering, Beihang University. His research interests include aircraft conceptual design and system of systems engineering.

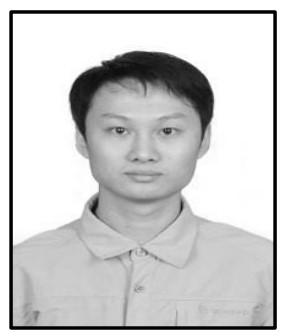

Jinpeng Bai, he is an engineer in Shenyang Aircraft Design and Research Institute. His research interests include aircraft conceptual design and system simulation.

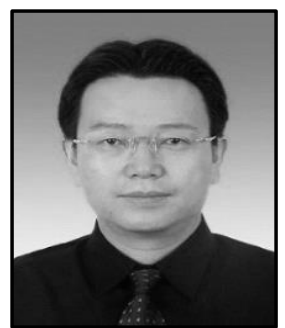

Zhe Wu, he is a professor in School of Aeronautical Science and Engineering, Beihang University. His research interests include aircraft conceptual design and near space vehicles design. 